\title{
Research on Multi-Attribute Information Fusion for the Dynamic State of Inland River Vessels
}

\author{
Yaotian Fan ${ }^{1,3, a}$, Xianzhang $\mathrm{Xu}^{2, \mathrm{~b}}$, Wang, Chi Wang ${ }^{1, \mathrm{c}}$ \\ ${ }^{1}$ School of Navigation, Wuhan University of Technology, Wuhan, China, 430063 \\ ${ }^{2}$ Faculty of Engineering and the Environment, University of Southampton, Southampton, \\ Hampshire, The United Kingdom, SO17 1BJ \\ ${ }^{3}$ Hubei Key Laboratory of Inland Shipping Technology, Wuhan, China, 430063 \\ aemail: fan.yaotian@163.com, bemail:xx1u14@soton.ac.uk, ${ }^{\mathrm{c} e m a i l:}$ \\ 1058277631@qq.com
}

\begin{abstract}
Key words: Information Fusion; Adaptive Weighting; BP Neural Network; Kalman filtering
Abstract: The perception and discrimination of the traffic environment and the state of the ship are greatly hindered and restricted during the ship operation under complex weather conditions, especially in the inland river, port and other restricted waters. Aiming at the multi-source, multidimensional and heterogeneous information of ship borne sensors, the dynamic information fusion model is constructed to improve the perception and discrimination ability of the crew to the target vessels in inland waterway. Based on the analysis of the limitations and complementarities of the ship borne navigation equipment in the discrimination of the ship's dynamic state, the multi-source heterogeneous data fusion model is constructed of Kalman filtering, the adaptive weighted fusion method and neural network model, the data were simulated and measured in real conditions to verify the model and determine the system's reliability, stability and accuracy.
\end{abstract}

\section{Introduction}

The research on the ship driving area is mainly concentrated on the data fusion of the multiple ship borne sensors to support the ship collision avoidance decision-making. Since Radar and Automatic Identification System (AIS) is the principal navigation equipment now, the information fusion research focuses on the data correlation and fusion from Radar and AIS. This paper studies on the data fusion from Radar and AIS.

In the area of applying statistics and weighting method to information fusion, S J Chang [1] suggested to fuse the data of Radar and AIS according to the errors using weighting fusion method. J C Zheng, Z H Chen [2] added neural network into statistics weighting method to improve the accuracy of the algorithm. Lin [3] proposed a modified fusion method based on the maximum membership principle which makes the related decision by time and distance then obtained the target in a settled range before accurate correlating using Cauchy membership function. In the aspect of information fusion based on BP neural network, X Hu, C Lin [4] applied BP neural network theory to correlate the target Radar and AIS information with a detailed analysis of the network structure, then it was simulated in MATLAB and the results showed that this method could make the different target information correlated. For the research on the information fusion based on Kalman filtering method, Yu [5] analyzed the Radar and AIS data in multi-dimensional way. Steady Kalman filtering method was applied to calibrate time and space, correlate data and fuse the track. A test was carried out to simulate and value the stability and accuracy of this algorithm.

Statistics weighting method can improve the accuracy and precision of the fusion, but it may enhance the complexity of the algorithm and the fusion choice needs to be determined by the data type. For BP neural network data fusion, the varying of network structure coefficients and the threshold would have significant influence on the results, and the size of data requires the different network coefficients so it needs to find the rule in research. Kalman filtering requires the reliability of real data and the stability of the filter in some degree. When the reliability of data is not enough 
or the stability is low, it would greatly affect the average of observed value and Kalman filtering estimate value [6]. The integration of multiple fusion method can avoid the unsatisfactory phenomena when using single fusion method.

\section{Integrating Model}

Most papers relating to Radar and AIS information fusion apply single method, this is because the traffic flow density on the sea is not very high and single method can satisfy the accuracy requirements of information correlation. But for inland river waters the traffic flow is much more intensive and complex, it needs higher reliability. This paper constructed a multi-source heterogeneous model integrating Kalman filtering, adaptive weighting and BP neural network, see Fig. 1.

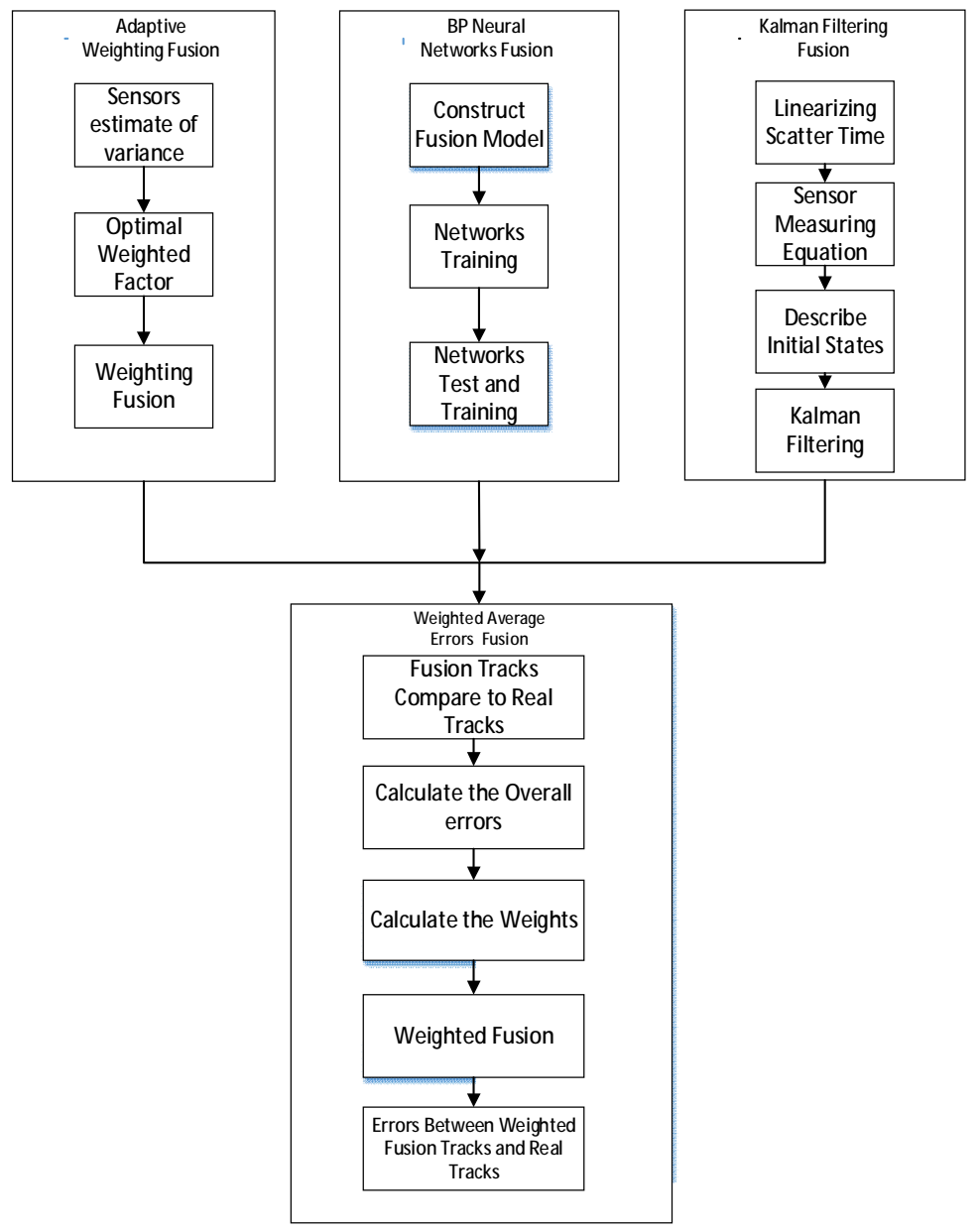

Fig. 1. Methodology

\section{Data Fusion}

Many information fusion model were proposed these years. The main method in data fusion is multilevel processing which the data fusion model can be separated as two types: the function model constructed according to the nodes sequence and the data model constructed according to the data extracted. This paper applies a mixed model based on controlling the circuit structure. Considering to the loop properties in information fusion processing, it tries to acquire higher accuracy of the task processing description and make it easier to obtain the positions where fusion happened. The methods applied in this model include adaptive weighting, BP neural network and Kalman filtering. 


\section{Adaptive Weighted Track Fusion}

\section{a. Optimal Weighted Factors}

Assuming the real value of the target track is $\mathrm{x}$ on $\mathrm{k}$ moment in the system. The independent value measured by AIS and Radar is $x_{i}$ and $x_{j}$ respectively which are the unbiased estimation of the real value $\mathrm{x}$. The error variance measured by AIS is $\delta_{1}^{2}$, weighted factor is $\mathrm{w}_{1}$; the error variance measured by AIS is $\delta_{2}^{2}$, weighted factor is $w_{2}$, fused value is X. These factors satisfy:

$$
\begin{gathered}
X=w_{1} x_{1}+w_{2} x_{2} \\
1=w_{1}+w_{2}
\end{gathered}
$$

The overall mean square error is

$$
\delta^{2}=\mathrm{E}\left[(\mathrm{x}-\mathrm{X})^{2}\right]=\mathrm{E}\left[\sum_{\mathrm{p}=1}^{2} \mathrm{w}_{\mathrm{p}}^{2}\left(\mathrm{x}-\mathrm{x}_{\mathrm{p}}\right)^{2}+2 \sum_{\substack{\mathrm{p}=1 \\ \mathrm{q}=1 \\ \mathrm{p} \neq \mathrm{q}}}^{2} w_{\mathrm{p}} w_{\mathrm{q}}\left(\mathrm{x}-\mathrm{x}_{\mathrm{p}}\right)\left(\mathrm{x}-\mathrm{x}_{\mathrm{q}}\right)\right] .
$$

After derivation, when $\delta_{2}^{2}$ is minimum, $w_{1}=\frac{\delta_{2}^{2}}{\delta_{1}^{2}+\delta_{2}^{2}}, w_{2}=\frac{\delta_{1}^{2}}{\delta_{1}^{2}+\delta_{2}^{2}}$, and

$$
\delta^{2}=\frac{\delta_{1}^{2} \delta_{2}^{2}}{\delta_{1}^{2}+\delta_{2}^{2}}
$$

\section{b. Weighted Fusion Algorism}

Under the situation that the measurement variance and weighted factors are known, it can derive the fused variance, distance, direction, Speed Over Ground (SOG) and course:

$$
\begin{gathered}
\delta_{\mathrm{X}_{\mathrm{ij}}(\mathrm{k})}^{2}=\frac{\delta_{\mathrm{ad}}^{2} \delta_{\mathrm{rd}}^{2}}{\delta_{\mathrm{ad}}^{2}+\delta_{\mathrm{rd}}^{2}} \\
\delta_{\mathrm{Y}_{\mathrm{ij}}(\mathrm{k})}^{2}=\frac{\delta_{\mathrm{a} \theta}^{2} \delta_{\mathrm{r} \theta}^{2}}{\delta_{\mathrm{a} \theta}^{2}+\delta_{\mathrm{r \theta}}^{2}} \\
\mathrm{X}_{\mathrm{ij}}(\mathrm{k})=\mathrm{w}_{\mathrm{ad}} \mathrm{X}_{\mathrm{Ai}}(\mathrm{k})+\mathrm{w}_{\mathrm{rd}} \mathrm{X}_{\mathrm{Ri}}(\mathrm{k})=\frac{\delta_{\mathrm{rd}}^{2}}{\delta_{\mathrm{ad}}^{2}+\delta_{\mathrm{rd}}^{2}} \mathrm{X}_{\mathrm{Ai}}(\mathrm{k})+\frac{\delta_{\mathrm{ad}}^{2}}{\delta_{\mathrm{ad}}^{2}+\delta_{\mathrm{rd}}^{2}} \mathrm{X}_{\mathrm{Ri}}(\mathrm{k}) \\
\mathrm{Y}_{\mathrm{ij}}(\mathrm{k})=\mathrm{w}_{\mathrm{a} \theta} \mathrm{Y}_{\mathrm{Ai}}(\mathrm{k})+\mathrm{w}_{\mathrm{r} \theta} \mathrm{Y}_{\mathrm{Ri}}(\mathrm{k})=\frac{\delta_{\mathrm{r} \theta}^{2}}{\delta_{\mathrm{a} \theta}^{2}+\delta_{\mathrm{r} \theta}^{2}} \mathrm{Y}_{\mathrm{Ai}}(\mathrm{k})+\frac{\delta_{\mathrm{ad}}^{2}}{\delta_{\mathrm{a} \theta}^{2}+\delta_{\mathrm{r} \theta}^{2}} \mathrm{Y}_{\mathrm{Ri}}(\mathrm{k})
\end{gathered}
$$

\section{BP Neural Network Fusion}

\section{a. Constructing Fusion Model}

First step is setting the input, output, hidden nodes, target error of network, training times, learning rate respectively, then it starts training with training data [7]. After the fusion model is constructed, training the network until it meets the setting requirements then inputting correlated AIS and Radar data and the consolidated information of network output can be obtained.

\section{b. Network Testing and Verifying}

After extracting $\mathrm{n}$ sets of AIS and Radar data to train the network, it turns to test and verify the training [9]. This paper uses the equation $\overline{\mathrm{E}_{\mathrm{k}}}=\frac{1}{\mathrm{~N}} \sum_{\mathrm{i}=1}^{\mathrm{N}}\left|\mathrm{D}_{\mathrm{k}}^{\mathrm{F}}(\mathrm{i})-\mathrm{D}_{\mathrm{k}}^{\mathrm{I}}(\mathrm{i})\right|$ to evaluate the network. $\mathrm{D}_{\mathrm{k}}^{\mathrm{F}}(\mathrm{i})$ is the kth characteristic value on i moment after training, F represents the data after BP neural network fusion; $D_{k}^{I}(i)$ is the kth characteristic value of the vessel on $i$ moment, I represents the vessel's data.

To evaluate the fusion result, the equations $\overline{\mathrm{B}_{k}}=\frac{1}{\mathrm{~N}} \sum_{\mathrm{i}=1}^{\mathrm{N}}\left|\mathrm{D}_{\mathrm{k}}^{\mathrm{A}}(\mathrm{i})-\mathrm{D}_{\mathrm{k}}^{\mathrm{I}}(\mathrm{i})\right|$ and $\overline{\mathrm{C}_{\mathrm{k}}}=\frac{1}{\mathrm{~N}} \sum_{\mathrm{i}=1}^{\mathrm{N}}\left|\mathrm{D}_{\mathrm{k}}^{\mathrm{R}}(\mathrm{i})-\mathrm{D}_{\mathrm{k}}^{\mathrm{I}}(\mathrm{i})\right|$ were applied here which represents the difference between AIS/Radar data and real value respectively. $\mathrm{D}_{\mathrm{k}}^{\mathrm{A}}(\mathrm{i})$ is the kth characteristic value of AIS data on i moment, A 
represents AIS data; $D_{k}^{R}(i)$ is the kth characteristic value of Radar data on i moment, $R$ represents the Radar data.

\section{Kalman Filtering Fusion}

The fundamental theory of fusing Radar and AIS data is correlating the data from these two sensors in time and space according to a kind of criterion and obtain a more reasonable and accurate fused data which is better than single sensor. The function of Kalman state estimation is able to smooth the AIS and Radar data, filter the measured vessel data and forecast the tracks in the future. Kalman filtering theory applies time domain recursion method to derive the optimal estimated value according to the state function tools [10].

The process of estimating the target state by data fusion in this paper shows as:

$$
\begin{array}{r}
\widehat{\mathrm{X}}(\mathrm{k}+1 \mid \mathrm{k}+1)=[\mathrm{I}-\mathrm{K}(\mathrm{k}+1) \mathrm{H}(\mathrm{k}+1)] \mathrm{X}(\mathrm{k}+1 \mid \mathrm{k})+\mathrm{K}(\mathrm{k}+1) \mathrm{Z}(\mathrm{k}+1) \\
=\mathrm{I}-\mathrm{K}(\mathrm{k}+1) \mathrm{H}(\mathrm{k}+1)=\mathrm{P}(\mathrm{k}+1 \mid \mathrm{k}+1) \mathrm{P}(\mathrm{k}+1 \mid \mathrm{k})^{-1}
\end{array}
$$

For AIS and Radar,

$$
\begin{gathered}
\mathrm{I}-\mathrm{I}-\mathrm{P}_{\mathrm{i}}(\mathrm{k}+1 \mid \mathrm{k}+1)^{-1} \mathrm{H}_{\mathrm{i}}(\mathrm{k}+1)^{\prime} \mathrm{R}_{\mathrm{i}}(\mathrm{k}+1)^{-1} \mathrm{H}_{\mathrm{i}}(\mathrm{k}+1) \\
=\mathrm{P}_{\mathrm{i}}(\mathrm{k}+1 \mid \mathrm{k}+1) \mathrm{P}_{\mathrm{i}}(\mathrm{k}+1 \mid \mathrm{k})^{-1} \\
\mathrm{H}_{\mathrm{i}}(\mathrm{k}+1)^{\prime} \mathrm{R}_{\mathrm{i}}(\mathrm{k}+1)^{-1} \mathrm{Z}_{\mathrm{i}}(\mathrm{k}+1)=\mathrm{P}_{\mathrm{i}}(\mathrm{k}+1 \mid \mathrm{k}+1)^{-1} \widehat{\mathrm{X}_{1}}(\mathrm{k}+1 \mid \mathrm{k}+1) \\
-\mathrm{P}_{\mathrm{i}}(\mathrm{k}+1 \mid \mathrm{k}+1)^{-1} \widehat{\mathrm{X}_{1}}(\mathrm{k}+1 \mid \mathrm{k}) .
\end{gathered}
$$

It can be derived that

$\widehat{\mathrm{X}_{1}}(\mathrm{k}+1 \mid \mathrm{k}+1)$

$$
\begin{aligned}
& =\mathrm{P}(\mathrm{k}+1 \mid \mathrm{k}+1)\left\{\mathrm{P}_{\mathrm{i}}(\mathrm{k}+1 \mid \mathrm{k})^{-1} \widehat{\mathrm{X}_{1}}(\mathrm{k}+1 \mid \mathrm{k})\right. \\
& \left.+\sum_{\mathrm{i}=1}^{2} \mathrm{P}_{\mathrm{i}}(\mathrm{k}+1 \mid \mathrm{k}+1)^{-1} \widehat{\mathrm{X}}_{1}(\mathrm{k}+1 \mid \mathrm{k}+1)-\mathrm{P}_{\mathrm{i}}(\mathrm{k}+1 \mid \mathrm{k})^{-1} \widehat{\mathrm{X}_{1}}(\mathrm{k}+1 \mid \mathrm{k})\right\} \\
& \widehat{\mathrm{X}_{1}}(\mathrm{k}+1 \mid \mathrm{k})=\Phi(\mathrm{k}) \widehat{\mathrm{X}_{1}}(\mathrm{k} \mid \mathrm{k}) \\
& \mathrm{P}_{\mathrm{i}}(\mathrm{k}+1 \mid \mathrm{k}+1)^{-1}=\mathrm{P}_{\mathrm{i}}(\mathrm{k}+1 \mid \mathrm{k})^{-1}+\sum_{\mathrm{i}=1}^{2} \mathrm{P}_{\mathrm{i}}(\mathrm{k}+1 \mid \mathrm{k}+1)^{-1}-\mathrm{P}_{\mathrm{i}}(\mathrm{k}+1 \mid \mathrm{k})^{-1} \\
& \mathrm{P}(\mathrm{k}+1 \mid \mathrm{k})=\Phi(\mathrm{k}) \mathrm{P}(\mathrm{k} \mid \mathrm{k}) \Phi(\mathrm{k})^{\prime}+\mathrm{G}(\mathrm{k}) \mathrm{Q}(\mathrm{k}) \mathrm{G}(\mathrm{k})^{\prime} .
\end{aligned}
$$

\section{Integrated Fusion}

\section{Integrated Data Fusion}

The errors between fused data and real value through different methods may be very significant. This paper compares the error of those three methods above, then use weighted average methods to acquire the weights of the three methods, and finally obtaining the final fused data. The weights can be derived from:

$$
\begin{aligned}
& \sigma_{1}=\sum_{\mathrm{i}=1}^{\mathrm{n}}\left(\mathrm{x}_{\mathrm{aw}}(\mathrm{i})-\mathrm{x}(\mathrm{i})\right)^{2}, \\
& \sigma_{2}=\sum_{\mathrm{i}=1}^{\mathrm{n}}\left(\mathrm{x}_{\mathrm{BP}}(\mathrm{i})-\mathrm{x}(\mathrm{i})\right)^{2}, \\
& \sigma_{3}=\sum_{\mathrm{i}=1}^{\mathrm{n}}\left(\mathrm{x}_{\mathrm{km}}(\mathrm{i})-\mathrm{x}(\mathrm{i})\right)^{2}, \\
& \delta_{1}=\sum_{\mathrm{i}=1}^{\mathrm{n}}\left(\mathrm{y}_{\mathrm{aw}}(\mathrm{i})-\mathrm{y}(\mathrm{i})\right)^{2}, \\
& \delta_{2}=\sum_{\mathrm{i}=1}^{\mathrm{n}}\left(\mathrm{y}_{\mathrm{BP}}(\mathrm{i})-\mathrm{y}(\mathrm{i})\right)^{2}, \\
& \delta_{3}=\sum_{\mathrm{i}=1}^{\mathrm{n}}\left(\mathrm{y}_{\mathrm{km}}(\mathrm{i})-\mathrm{y}(\mathrm{i})\right)^{2}
\end{aligned}
$$

The $\mathrm{x}$ and $\mathrm{y}$ coordinates of the adaptive fusion track based on average weighted equations are 
$\omega_{\mathrm{x} 1}=\frac{\sigma_{2}+\sigma_{3}}{2\left(\sigma_{1}+\sigma_{2}+\sigma_{3}\right)}$ and $\omega_{\mathrm{y} 1}=\frac{\left(\delta_{2}+\delta_{3}\right)}{2\left(\delta_{1}+\delta_{2}+\delta_{3}\right.}$ respectively.

The $x$ and $y$ coordinates of the BP neural network fusion are $\omega_{\mathrm{x} 2}=\frac{\sigma_{1}+\sigma_{3}}{2\left(\sigma_{1}+\sigma_{2}+\sigma_{3}\right)}$ and $\omega_{y 2}=\frac{\left(\delta_{1}+\delta_{3}\right)}{2\left(\delta_{1}+\delta_{2}+\delta_{3}\right.}$ respectively.

The $\mathrm{x}$ and $\mathrm{y}$ coordinates of the Kalman filtering fusion are $\omega_{\mathrm{x} 3}=\frac{\sigma_{1}+\sigma_{2}}{2\left(\sigma_{1}+\sigma_{2}+\sigma_{3}\right)}$ and $\omega_{y 3}=\frac{\left(\delta_{1}+\delta_{2}\right)}{2\left(\delta_{1}+\delta_{2}+\delta_{3}\right.}$ respectively.

So the fused track can be expressed as:

$$
\begin{gathered}
\mathrm{x}_{\mathrm{r}}(\mathrm{k})=\frac{\sigma_{2}+\sigma_{3}}{2\left(\sigma_{1}+\sigma_{2}+\sigma_{3}\right)} * \mathrm{x}_{\mathrm{aw}}(\mathrm{k})+\frac{\sigma_{1}+\sigma_{3}}{2\left(\sigma_{1}+\sigma_{2}+\sigma_{3}\right)} * \mathrm{x}_{\mathrm{BP}}(\mathrm{k})+\frac{\sigma_{1}+\sigma_{2}}{2\left(\sigma_{1}+\sigma_{2}+\sigma_{3}\right)} * \mathrm{x}_{\mathrm{km}}(\mathrm{k}) \\
\mathrm{y}_{\mathrm{r}}(\mathrm{k})=\frac{\delta_{2}+\delta_{3}}{2\left(\delta_{1}+\delta_{2}+\delta_{3}\right)} * \mathrm{y}_{\mathrm{aw}}(\mathrm{k})+\frac{\delta_{1}+\delta_{3}}{2\left(\delta_{1}+\delta_{2}+\delta_{3}\right)} * \mathrm{y}_{\mathrm{BP}}(\mathrm{k})+\frac{\delta_{1}+\delta_{2}}{2\left(\delta_{1}+\delta_{2}+\delta_{3}\right)} * \mathrm{y}_{\mathrm{km}}(\mathrm{k}),
\end{gathered}
$$

where $\mathrm{x}_{\mathrm{aw}}(\mathrm{k})$ is $\mathrm{x}$ coordinate of the fused point from adaptive weighted track on $\mathrm{k}$ moment, $\mathrm{x}_{\mathrm{BP}}(\mathrm{k})$ is $\mathrm{x}$ coordinate of the fused point from BP neural network, $\mathrm{x}_{\mathrm{km}}(\mathrm{k})$ is $\mathrm{x}$ coordinate of the fused point from Kalman filtering.

Additionally, $\mathrm{y}_{\mathrm{aw}}(\mathrm{k})$ is $\mathrm{y}$ coordinate of the fused point from adaptive weighted track on $\mathrm{k}$ moment, $\mathrm{y}_{\mathrm{BP}}(\mathrm{k})$ is y coordinate of the fused point from BP neural network, $y_{\mathrm{km}}(\mathrm{k})$ is y coordinate of the fused point from Kalman filtering.

\section{The Accuracy and Stability of the Integrated System}

\section{a. Accuracy}

The coordinates of the adaptive weighted fusion track points on $\mathrm{k}$ moments were defined as $\left(\mathrm{x}_{\mathrm{aw}}(\mathrm{k}), \mathrm{y}_{\mathrm{aw}}(\mathrm{k})\right)$, while for BP neural network were $\left(\mathrm{x}_{\mathrm{BP}}(\mathrm{k}), \mathrm{y}_{\mathrm{BP}}(\mathrm{k})\right)$ and for Kalman filtering were $\left(\mathrm{x}_{\mathrm{km}}(\mathrm{k}), \mathrm{y}_{\mathrm{km}}(\mathrm{k})\right)$, so the coordinates of integrated fusion track points were $\left(\mathrm{x}_{\mathrm{t}}(\mathrm{k}), \mathrm{y}_{\mathrm{t}}(\mathrm{k})\right)$ while the real track points were $(\mathrm{x}(\mathrm{k}), \mathrm{y}(\mathrm{k}))$; the volatility of error can be treated as the accuracy of fusion since the low volatility of error shows a high accuracy of the fusion, the volatility of error can be expressed as:

$$
\begin{aligned}
& \mathrm{B}=\sqrt{\frac{\left(\delta_{\mathrm{k}}-\bar{\delta}\right)^{2}}{\mathrm{n}-1}} \\
& \delta_{\mathrm{k}}=\sqrt{\left(\mathrm{x}_{\mathrm{r}}(\mathrm{k})-\mathrm{x}(\mathrm{k})\right)^{2}+\left(\mathrm{y}_{\mathrm{r}}(\mathrm{k})-\mathrm{y}(\mathrm{k})\right)^{2}},
\end{aligned}
$$

where $\delta_{\mathrm{k}}$ is the error between fused track points and real track points; $\bar{\delta}$ is the average of $\delta_{\mathrm{k}}$; $\left(\mathrm{x}_{\mathrm{r}}(\mathrm{k}), \mathrm{y}_{\mathrm{r}}(\mathrm{k})\right)$ is the fused track points on k moment, $(\mathrm{x}(\mathrm{k}), \mathrm{y}(\mathrm{k}))$ represents the real track points on $\mathrm{k}$ moment.

So the accuracy of adaptive weighting fusion can be

$$
\mathrm{B}_{\mathrm{aw}}=\sqrt{\frac{\left(\delta_{\mathrm{kaw}}-\bar{\delta}\right)^{2}}{\mathrm{n}-1}}
$$

the accuracy of BP neural network fusion can be

$$
\mathrm{B}_{\mathrm{BP}}=\sqrt{\frac{\left(\delta_{\mathrm{kBP}}-\bar{\delta}\right)^{2}}{\mathrm{n}-1}}
$$

the accuracy of Kalman filtering fusion can be

$$
\mathrm{B}_{\mathrm{km}}=\sqrt{\frac{\left(\delta_{\mathrm{kkm}}-\bar{\delta}\right)^{2}}{\mathrm{n}-1}}
$$


and the accuracy of integrated fusion can be

$$
B_{j}=\sqrt{\frac{\left(\delta_{k j}-\bar{\delta}\right)^{2}}{n-1}}
$$

\section{b. Stability}

The stability of the fusion track is the sum of the difference value between the adjacent track points.

$$
\begin{aligned}
& \Delta_{\mathrm{k}}=\sqrt{\left(\mathrm{x}_{\mathrm{k}}-\mathrm{x}_{\mathrm{k}-1}\right)^{2}-\left(\mathrm{y}_{\mathrm{k}}-\mathrm{y}_{\mathrm{k}-1}\right)^{2}} \\
& \quad \sum_{\mathrm{k}=2}^{\mathrm{n}} \Delta_{\mathrm{k}}=\sum_{\mathrm{k}=2}^{\mathrm{n}} \sqrt{\left(\mathrm{x}_{\mathrm{k}}-\mathrm{x}_{\mathrm{k}-1}\right)^{2}-\left(\mathrm{y}_{\mathrm{k}}-\mathrm{y}_{\mathrm{k}-1}\right)^{2}} .
\end{aligned}
$$

So the stability of adaptive weighting fusion can be

$$
\sum_{\mathrm{k}=2}^{\mathrm{n}} \Delta_{\mathrm{kaw}}=\sum_{\mathrm{k}=2}^{\mathrm{n}}\left(\sqrt{\left(\mathrm{x}_{\text {kaw }}-\mathrm{x}_{(\mathrm{k}-1) \mathrm{aw}}\right)^{2}-\left(\mathrm{y}_{\text {kaw }}-\mathrm{y}_{(\mathrm{k}-1) \mathrm{aw}}\right)^{2}}\right) ;
$$

the stability of BP neural network fusion can be

$$
\sum_{\mathrm{k}=2}^{\mathrm{n}} \Delta_{\mathrm{kBP}}=\sum_{\mathrm{k}=2}^{\mathrm{n}}\left(\sqrt{\left(\mathrm{x}_{\mathrm{kBP}}-\mathrm{x}_{(\mathrm{k}-1) \mathrm{BP}}\right)^{2}-\left(\mathrm{y}_{\mathrm{kBP}}-\mathrm{y}_{(\mathrm{k}-1) \mathrm{BP}}\right)^{2}}\right) ;
$$

the stability of Kalman filtering fusion can be

$$
\sum_{\mathrm{k}=2}^{\mathrm{n}} \Delta_{\mathrm{kkm}}=\sum_{\mathrm{k}=2}^{\mathrm{n}}\left(\sqrt{\left(\mathrm{x}_{\mathrm{kkm}}-\mathrm{x}_{(\mathrm{k}-1) \mathrm{km}}\right)^{2}-\left(\mathrm{y}_{\mathrm{kkm}}-\mathrm{y}_{(\mathrm{k}-1) \mathrm{km}}\right)^{2}}\right) ;
$$

and the stability of integrated fusion can be

$$
\sum_{\mathrm{k}=2}^{\mathrm{n}} \Delta_{\mathrm{kj}}=\sum_{\mathrm{k}=2}^{\mathrm{n}}\left(\sqrt{\left(\mathrm{x}_{\mathrm{kj}}-\mathrm{x}_{(\mathrm{k}-1) \mathrm{j}}\right)^{2}-\left(\mathrm{y}_{\mathrm{kj}}-\mathrm{y}_{(\mathrm{k}-1) \mathrm{j}}\right)^{2}}\right) .
$$

\section{Simulation and Verification}

In order to show the characteristics of the navigation of inland river vessel, not only the Radar and AIS data when the real vessel navigates straightly need to be collected, but also the data when the vessel makes substantial movements should be collected. Considering to the space limitation on inland river waters and the dangers might happen if the test was carried out in the complex traffic environment of inland river water, the verification test data were collected on the water along the coast in day time with good visibility. For the safety reasons for the test and the navigation order, the test vessel was chosen as pilot vessel which is maneuverable comparing to the big ship. The test route started from No. 6 Wharf in Qingdao Dagang to Tuan Island in Jiaozhou Gulf then returned.

The test was carried out as: Choosing the vessel "Pilot No.2" in Qingdao Pilot Station as target vessel, the radar data was simulated in Qingdao VTS Centre to tracing the vessel "Pilot No.2" in time. Meanwhile, the AIS and Radar data of target vessel and vessels nearby such as longitudes, latitudes, speed, course and so on were collected. On the other hand, a DGPS was installed on the target vessel of which the antenna of it was close to that of ship borne GPS, the data like longitudes, latitudes, speed, course were measured and collected. The DGPS data were considered as a reference when verifying the fusion model because of its higher accuracy. The Radar and AIS data were correlated firstly, then it fused the collected AIS and Radar data according to those three methods introduced in Chapter 3.

The quadratic sum error of $\mathrm{x}$ coordinate and $\mathrm{y}$ coordinate derived from the adaptive weighted track method are $\sigma_{1}=1992.214$ and $\delta_{1}=8369.744$; the quadratic sum error of $\mathrm{x}$ coordinate and $\mathrm{y}$ coordinate derived from the BP neural network method are $\sigma_{2}=4792.249$ and $\delta_{2}=28594.4$; the quadratic sum error of x coordinate and y coordinate derived from the Kalman filtering method are $\sigma_{3}=4764.492957$ and $\delta_{3}=28804.28979$.

From the average weighted equation, it can be obtained:

the weights of $\mathrm{x}$ coordinate and $\mathrm{y}$ coordinate derived from the adaptive weighted track method 
are $\omega_{\mathrm{x} 1}=\frac{\sigma_{2}+\sigma_{3}}{2\left(\sigma_{1}+\sigma_{2}+\sigma_{3}\right)}=0.4137$ and $\omega_{\mathrm{y} 1}=\frac{\left(\delta_{2}+\delta_{3}\right)}{2\left(\delta_{1}+\delta_{2}+\delta_{3}\right.}=0.4364$;

the weights of $\mathrm{x}$ coordinate and $\mathrm{y}$ coordinate derived from the BP neural network method are $\omega_{\mathrm{x} 2}=\frac{\sigma_{1}+\sigma_{3}}{2\left(\sigma_{1}+\sigma_{2}+\sigma_{3}\right)}=0.2925$ and $\omega_{\mathrm{y} 2}=\frac{\left(\delta_{1}+\delta_{3}\right)}{2\left(\delta_{1}+\delta_{2}+\delta_{3}\right.}=0.2826$;

the weights of $\mathrm{x}$ coordinate and $\mathrm{y}$ coordinate derived from the Kalman filtering method is $\omega_{\mathrm{x} 3}=\frac{\sigma_{1}+\sigma_{2}}{2\left(\sigma_{1}+\sigma_{2}+\sigma_{3}\right)}=0.2937$ and $\omega_{\mathrm{y} 3}=\frac{\left(\delta_{1}+\delta_{2}\right)}{2\left(\delta_{1}+\delta_{2}+\delta_{3}\right.}=0.2810$;

So the fusion track can be expressed as

$$
\begin{aligned}
& \mathrm{x}_{\mathrm{r}}=0.4137 * \mathrm{x}_{\mathrm{aw}}(\mathrm{k})+0.2925 * \mathrm{x}_{\mathrm{BP}}(\mathrm{k})+0.2937 * \mathrm{x}_{\mathrm{km}}(\mathrm{k}) \\
& \mathrm{y}_{\mathrm{r}}=0.4364 * \mathrm{y}_{\mathrm{aw}}(\mathrm{k})+0.2826 * \mathrm{y}_{\mathrm{BP}}(\mathrm{k})+0.2810 * \mathrm{y}_{\mathrm{km}}(\mathrm{k})
\end{aligned}
$$

The fused track is shown in Fig. 2.

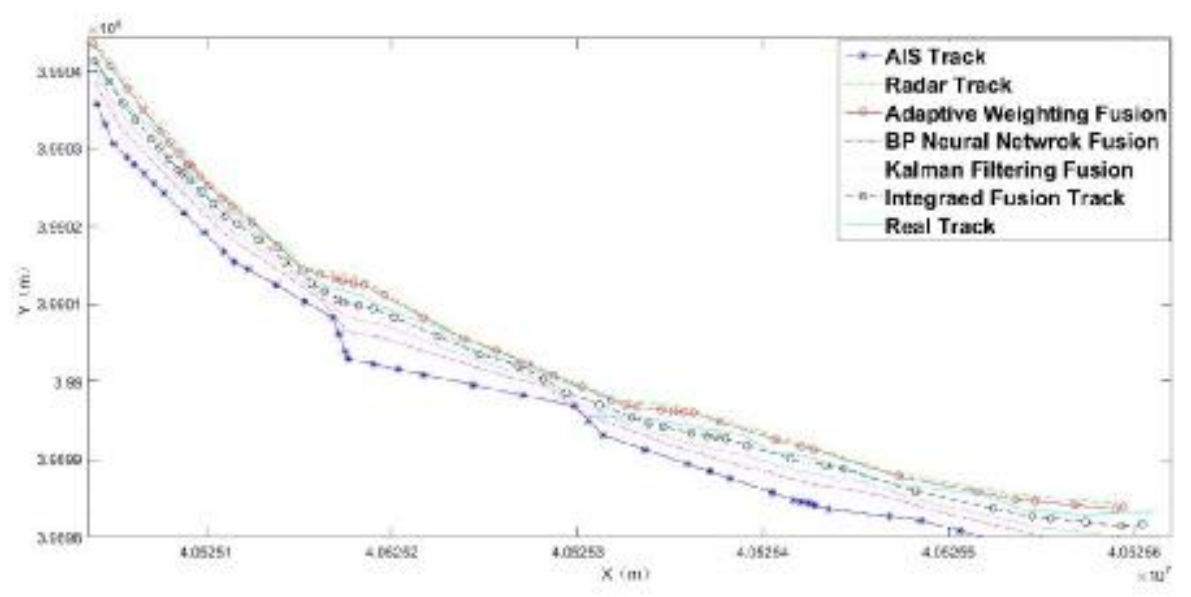

Fig. 2. The Track from Sensors and Fusion

\section{a. Accuracy}

It can be calculated that $\mathrm{B}_{\mathrm{aw}}=133.9834, \mathrm{~B}_{\mathrm{BP}}=762.5491, \mathrm{~B}_{\mathrm{km}}=314.2769, \mathrm{~B}_{\mathrm{j}}=4.3978$. It shows that the integrated model is much more accurate.

\section{b. Stability}

It derives that $\sum_{\mathrm{k}=2}^{\mathrm{n}} \Delta_{\mathrm{kaw}}=865.6005, \quad \sum_{\mathrm{k}=2}^{\mathrm{n}} \Delta_{\mathrm{kBP}}=877.1249, \quad \sum_{\mathrm{k}=2}^{\mathrm{n}} \Delta_{\mathrm{kkm}}=879.4183$, $\sum_{\mathrm{k}=2}^{\mathrm{n}} \Delta_{\mathrm{kj}}=869.9175$. It proves that the stability of integrated fusion is higher than those two single method.

\section{Conclusion}

This paper analyzed the limitations and complementarities of ship borne Radar and AIS in perceiving the inland river vessels' dynamic state. A multi-source heterogeneous data fusion model was constructed and verified by a computational test which shows the model can greatly improve the accuracy and stability while guaranteeing the reliability.

\section{References}

[1] Chang S J. Development and analysis of applications as an efficient tool for vessel traffic service[A]. MTS/IEEE OCEANS 04[C] U.S:2004:2249-2253.

[2] Zheng J C, Chen Z H. A Study of Radar and AIS Object Data Fusion Based on AFS_RBF's Neural Network[J]. JOURNAL OF JIMEI UNIVERSITY (NATURAL SCIENCE), 2005,10(3):28-32.

[3] Lin C. Algorithm and Simulation of Fuzzy Correlation of Tracks from Radar and AIS. [J] Journal of System Simulation. 2006(8): 903-905.

[4] X Hu, C Lin. A Preliminary Study on Targets Association Algorithm of Radar and AIS Using BP 
Neural Network[C]. Procedia Engineering, 2011:1441-1445.

[5] Yu Haixia. The Study of AIS and Radar Data Fusion Algorithm[D]. Dalian Maritime University, 2006.

[6] Liu Q, Zhong H, etc. Kalman Filter Fusion Algorithm and Its Application in Highly Precise Measurement of Liquid Level in Ship Tank[J]. Shipbuilding of China, 2016, 57(2):192-200

[7] Guo Wengang. BP neural network based ship tracking control technology[J]. Ship Science and Technology, 2014(8):87-93

[8] Hu Xiaorui. Research on Targets Information Fusion of Radar and AIS Based on BP Neural Network [D]. Jimei University, 2012.

[9] Zhang Li. Ship motion estimation based on BP neural network[J]. Ship Science and Technology, 2016(12):13-15

[10] Xu T, Cai F, etc. Research on estimation of AIS vessel trajectory data based on Kalman filter algorithm[J]. Modern Electronics Technique, 2014(5):97-100 